\title{
Failure Factors of Teaching English as a Second Language Students in teaching Graduate Programme at Institute of Teacher Education
}

\author{
Muhammad Akbar Zahidi* \\ Faculty of Education, University of Malaya, MALAYSIA \\ *Corresponding author: akbar_zahidi@yahoo.co.uk
}

Received July 28, 2014; Revised August 08, 2014; Accepted September 24, 2014

\begin{abstract}
This study was about the failure factors of Teaching English as a Second Language (TESL) students in teaching graduate programme (TGP) at institute of teacher education (ITE). Thus, this study identified the factors of failure from personal problems, lecturer, facility, syllabus and school factors. Furthermore, this study used a mixed mode method such as semi-structural interview and questionnaires. To answer the interview instrument, a total of 12 TGP students were selected from maximum variation method based on six different zones. Then, to answer the questionnaires, this research involved 40 TGP students at random. Next, descriptive statistics of SPSS 21.0 software was used to analyze the factors in five domains. The findings of the study indicated that the domain of syllabus factors contributed to the cause of the failure at the highest level. However, the finding of the lecturer communication was the highest among the items. Therefore, failure was causing some effects such as feeling sad, frustrated and stressed out to deal with colleagues and family members.
\end{abstract}

Keywords: Teaching English as a Second Language (TESL) Students, Teaching Graduate Program (TGP), Institute of Teacher Education (ITE)

Cite This Article: Muhammad Akbar Zahidi, "Failure Factors of Teaching English as a Second Language Students in teaching Graduate Programme at Institute of Teacher Education." American Journal of Educational Research, vol. 2, no. 10 (2014): 850-855. doi: 10.12691/education-2-10-2.

\section{Introduction}

Teaching Graduate Program (TGP) offered to in service teachers who are under the Ministry of Education to uphold their teaching profession as contained in the Education Development Plan Blueprint 2013-2025 to ensure that all teachers have qualifications at least at the undergraduate level [5]. TGP goals were to raise the level of educational qualification of Postgraduate Diploma in Education Services (PDES) as well as to produce quality graduates, including in the field of TESL in terms of mastery knowledge, skills and competencies of professionalism in line with the National Education Philosophy and Education Teachers Philosophy [1]. So, this program was very important to increase the number of graduate teachers in primary schools over $60 \%$ from the total before 2015. The goal line with the government transformation programme launched a new offer for all teachers to improve service quality and increase profile of professionalism in their careers [3].

Therefore, ITE offered to 13,213 students for TGP at ITE in June 2011, including the option or field of TESL. However, the results of first semester of that year showed a total of 140 TGP students failed the examination [4]. After repetitions of examinations were carried out, a total of 23 TGP students (30\%) still failed and stopped. A total number of students who failed in this TGP was very large compared to the number of pre-service students in Bachelor of Teaching which was only five people in 2011, even though both groups of the students were to follow the same curriculum structure [6]. Further, Halim [6] found that 40 TGP students of TESL options failed in some courses until 2013 and now they still continue their studies. Therefore, this research will identify the level of failure based on five domains in the TGP.

\section{Review of Literature}

The failure of TGP students in TESL at ITE was due to several factors. Based on previous studies, some preliminary findings showed that there were a few reasons contributing to the factors such as personal problems, lecturers, facilities, syllabus and schools. According to Sulan [2], through the failure of off-campus students at a local university, personal factors were a major cause and showed $76 \%$ respondents failed to finish their studies. This was because the students were in employment services. Besides, their ages were different from full time students and some of them were over 40 years old. Furthermore, some of them suffered from health problems but age was not a determinant of reaching a success. Then, students should be wise in choosing option or field offered for the distance education. 
Accordingly, the family was decisive to ensure a success to TGP students. This was because most of them were already married and have to juggle between family and education. Thus, sacrifice of time on weekends was a psychological toll that must be borne by the TGP students. Besides, one of the reasons for failures was due to the extra costs or fees. They had to get the knowledge is understood therefore it is unnecessary. TGP students had to be wise to choose their fields at the university and if not, they were getting some difficulties to follow the syllabus. Thus, encouragement from families and friends was very important for the students to be driven to succeed.

Moreover, according to Jamaluddin [3], the cause of the distance education students' failure was due to lecturers. The results showed that the absence of an attitude of respect was causing the failure. Adult students deserve to get a different learning approach from teenage students. Therefore, lecturers should respect adult learners through more effective discretion. Lecturers cannot be arbitrary resolute in delivering teaching and learning. Thus, teaching techniques need to be changed and require an understanding with a different approach to teach the students. Effective knowledge and techniques of communication caused the students not to understand what was being taught.

Further, a study from Rauzah and Muhammad [4] showed that the convenience factor for adult learners was not giving them satisfaction. Distance education students had to use facilities on weekends which were used by the previous full-time students. Besides, the other facilities factors such as ITE's toilets were not clean, tables and chairs were not enough, lack of an LCD projector, no internet connection, difficult to get the internet password and the lecture rooms were not clean [5]. All of these factors led to disruption of the adult learning.

Next, Halim [6] showed that syllabus factor for learning distance was too difficult and far on their level of knowledge. This led students to take additional classes to understand the syllabus in their studies. Syllabus was quite difficult, lack of practical learning and study period was too long. These factors resulted for the students not to continue their studies.

In addition, school factors were also involved in the failure of TGP distance students. This was due to lack of moral support at their workplaces. According to Jamaluddin [3], students who were in employment services needed encouragement and support by the administration of their organizations. Therefore, TGP students should not be burdened with too much work from their workplaces. Administrators in the organization should understand that performing various tasks in the same time required cooperation between each other. In conclusion, all adult students through distance education requires motivation and the surrounding circumstances need to be favorable.

\section{Methodology}

Research Design: In this study, the method used was quantitative and qualitative. This study used a descriptive design of description and narration. It used to describe an understanding of the failure factors of TESL students in TGP at ITE.
Sampling: To answer the interview instrument, a total of 12 student teachers were selected through maximum variation based on six different zones. Meanwhile, to answer the questionnaires, it was involving 40 students of TGP students randomly.

Instrument: The main instruments in this study were a set of interview and a questionnaire developed for identifying the main factors that caused the failure of TESL students in TGP at ITE. Interview instrument was developed through the findings of previous studies based on the objectives and research questions. Next, researchers built a set of questionnaires based on the findings from the interview. The questionnaire statements consisted of two parts which were Part A and Part B.

Part A contained profile of the respondents while Part B contained five main components which included personal factors, lecturer, facility, syllabus and school that contributed to the failures among the students. Further, the last aspect contained a few steps and suggestions from respondents to overcome these problems. The instruments used were developed by the researchers based on an interview pilot study that conducted towards 20 respondents in the Klang Valley one month before the actual research conducted. Accordingly, the questionnaire was constructed based on the findings from the pilot study.

\section{Validity and Reliability}

Furthermore, researchers used content validity to assess the validity of the questionnaire in this study. Based on a list of scores given by a panel of three experts, the Cronbach Alpha for the questionnaire instrument was 0.790 to 0.8 .19 . In conclusion, the Cronbach Alpha in content validity of this study was 0.806 .

Then, the researchers used "test-retest" to test the reliability level of expression in the instrument. The instrument was evaluated twice on the same sample group of 20 persons and analyzed through Pearson correlation to determine the strength of relationship. The results of this pilot study showed the reliability coefficient was 0.839 . Thus, the validity and reliability in this study was acceptable and suitable to be used.

\section{Data Analysis and Findings}

Table 1 showed that $35.0 \%$ of respondents were male and $65.0 \%$ of the respondents were female. In terms of age, $55.0 \%$ of students were 31 to 40 years old and $45.0 \%$ of the students were aged between 41 to 50 years old. Based on the categories of teaching experience, a total of $20.0 \%$ of the respondents were between 2 and 10 years. In addition, a total of $75.0 \%$ of the respondents were between 11 to 20 years. Meanwhile, a total of $5.0 \%$ of the respondents were between 21 to 30 years. For the original option category, a total of $40.0 \%$ of respondents were comprised of music education option.

However, only $20.0 \%$ of respondents were composed of science option. Next, the students' option/ field category showed a total of $10.0 \%$ of TGP respondents consisted of mathematics, tesl, physical education and islamic education options. Furthermore, the category of option or field chosen showed a total of $100.0 \%$ of the respondents chose TESL. 
Table 1. Profile of Survey Respondents by Gender, Age, Experience and Original Option/ Fields Offered at ITE

\begin{tabular}{|c|c|c|}
\hline Profile of Respondents & $\mathbf{N}$ & $\%$ \\
\hline \multicolumn{3}{|l|}{ Gender } \\
\hline Male & 14 & 35.0 \\
\hline Female & 26 & 65.0 \\
\hline TOTAL & 40 & 100.0 \\
\hline \multicolumn{3}{|l|}{ Age } \\
\hline $26-30$ years old & 0 & 0 \\
\hline $31-40$ years old & 22 & 55.0 \\
\hline $41-50$ years old & 18 & 45.0 \\
\hline 51 years old and above & 0 & 0 \\
\hline TOTAL & 40 & 100.0 \\
\hline \multicolumn{3}{|l|}{ Experience } \\
\hline $2-10$ years & 8 & 20.0 \\
\hline $11-20$ years & 30 & 75.0 \\
\hline $21-30$ years & 2 & 5.0 \\
\hline Over 31 years & 0 & 0 \\
\hline TOTAL & 40 & 100.0 \\
\hline \multicolumn{3}{|l|}{ Original Option/ Field } \\
\hline Mathematics & 4 & 10.0 \\
\hline TESL & 4 & 10.0 \\
\hline Physical Education & 8 & 20.0 \\
\hline Science Education & 8 & 20.0 \\
\hline Music Education & 16 & 40.0 \\
\hline TOTAL & 40 & 100.0 \\
\hline \multicolumn{3}{|l|}{ Option/ Field Chosen } \\
\hline TESL & 40 & 100.0 \\
\hline TOTAL & 40 & 100.0 \\
\hline
\end{tabular}

Table 2 showed that the personal factors contributing to the failure factors of TESL students in TGP at ITE with an overall mean with $M=3: 08, S D=1.076$ on average level. The study found that the difficulty factor in TGP field was a major factor in the failure with $M=3: 32, S D=1.010$ on average. The findings were in line with an interview. The views and perceptions of the respondent ware as follows:

Indeed ... I'm interested with my option of field chosen.. besides, I like TESL but it is very difficult for me to study because I have to use my physical.. but, learning in the institute changed everything.. sometimes, I'm enjoying learning TESL but I'm too old to learn TESL physically ... and the problem is, I don't get any support in terms of moral from anyone and I have some health problems. We really want to get good lecturers in ITE. I hope I can get a better future after finishing this study even though I have to pay tuition fees by myself to get knowledge.

(INF1/North/14.2.2014)

However, the factor of health problems was the least important factor with $M=2.84, S D=1.208$ on average level.

The findings were in line with the interviews. The views and perceptions of the respondents were as follows: ...our seniors in the ITE are not helping us so much.. I cannot remember so many points in the class maybe because of my age. Besides, my health is sometimes disrupted as well. I really hope that some young teachers can help me in my study. I can do all assignments given by written but it is difficult for me to use my physical at the field. Sometimes my lecturers just teach us without knowing that we are older than them and our ages caused we could not able to remember so much things in our studies... but, sometimes we are ashamed to admit that we do not know anything in front of the class.

(INF2/Middle/22.2.2014).

\begin{tabular}{|c|c|c|c|c|c|c|c|c|c|}
\hline \multirow[b]{2}{*}{ S.N. } & \multirow[b]{2}{*}{ Item } & \multicolumn{2}{|c|}{ Not Related } & \multicolumn{3}{|c|}{ Related } & \multirow[b]{2}{*}{ Mean } & \multirow[b]{2}{*}{ Standard Deviation } & \multirow[b]{2}{*}{ Level } \\
\hline & & SNR N (\%) & NT N (\%) & QR N (\%) & R N (\%) & SR N (\%) & & & \\
\hline 1 & Health problems & $14(35)$ & $14(35)$ & $2(5)$ & $10(25)$ & $0(0)$ & 2.84 & 1.208 & Average \\
\hline 2 & Option / field of study offered & $2(5)$ & $4(10)$ & $2(5)$ & $16(40)$ & $16(40)$ & 3.19 & .961 & Average \\
\hline 3 & Family encouragement & $6(15)$ & $6(15)$ & $4(10)$ & $4(10)$ & $20(50)$ & 2.95 & 1.069 & Average \\
\hline 4 & Sacrifice of time on weekends & $4(10)$ & $12(30)$ & $4(10)$ & $8(20)$ & $12(30)$ & 3.05 & 1.181 & Average \\
\hline 5 & Tuition fees & $16(40)$ & $12(30)$ & $2(5)$ & $6(15)$ & $4(10)$ & 3.25 & 1.033 & Average \\
\hline 6 & Difficulty field in TGP & $8(20)$ & $4(10)$ & $0(0)$ & $10(25)$ & $18(45)$ & 3.32 & 1.010 & Average \\
\hline \multirow[t]{2}{*}{7} & Friend encouragement & $4(10)$ & $8(20)$ & $4(10)$ & $6(15)$ & $18(45)$ & 2.95 & 1.069 & Average \\
\hline & & \multicolumn{5}{|c|}{ Overall Mean } & 3.08 & 1.076 & Average \\
\hline
\end{tabular}

SNR $\div$ Strongly Not Related; NR $\div$ Not Related; QR $\div$ Quite Related; R $\div$ Related; SR $\div$ Strongly Related.

Table 3. Lecturer Factors

\begin{tabular}{|c|c|c|c|c|c|c|c|c|c|}
\hline & & \multicolumn{2}{|c|}{ Not Related } & \multicolumn{3}{|c|}{ Related } & \multirow[b]{2}{*}{ Mean } & \multirow[b]{2}{*}{ Standard Deviation } & \multirow[b]{2}{*}{ Level } \\
\hline S.N. & Item & SNR N (\%) & NT N (\%) & QR N (\%) & R N (\%) & SR N (\%) & & & \\
\hline 1 & Attitude of respect & $2(5)$ & $2(5)$ & $4(10)$ & $8(20)$ & $24(60)$ & 2.96 & 1.216 & Average \\
\hline 2 & Lecturers service & $2(5)$ & $0(0)$ & $2(5)$ & $12(30)$ & $24(60)$ & 3.07 & 1.151 & Average \\
\hline 3 & Lecturer assertive & $2(5)$ & $4(10)$ & $6(15)$ & $8(20)$ & $18(45)$ & 2.96 & 1.179 & Average \\
\hline 4 & Teaching methods & $2(5)$ & $2(5)$ & $4(10)$ & $6(15)$ & $26(65)$ & 3.12 & 1.127 & Average \\
\hline 5 & Lecturer attraction & $4(10)$ & $4(10)$ & $2(5)$ & $8(20)$ & $22(55)$ & 3.29 & 1.007 & Average \\
\hline 6 & Teaching aids & $0(0)$ & $4(10)$ & $4(10)$ & $8(20)$ & $24(60)$ & 2.84 & 1.146 & Average \\
\hline 7 & Lecturer's communication & $0(\mathbf{0})$ & $\mathbf{0}(\mathbf{0})$ & $2(5)$ & $14(35)$ & $24(60)$ & 4.96 & 1.216 & High \\
\hline \multirow[t]{2}{*}{8} & Lecturer's knowledge & $0(0)$ & $2(5)$ & $4(10)$ & $14(35)$ & $20(50)$ & 4.07 & 1.151 & High \\
\hline & & \multicolumn{5}{|c|}{ Overall Mean } & 3.40 & 1.149 & Average \\
\hline
\end{tabular}

SNR $\div$ Strongly Not Related; NR $\div$ Not Related; QR $\div$ Quite Related; R $\div$ Related; SR $\div$ Strongly Related.

Table 3 showed that the lecturer factors contributing to level. The findings were in line with the interviews. The the failure factors of TESL students in TGP at ITE with an overall mean with $M=3.40$ and $S D=1.149$ on average level. The study found that the factor of communication with the lecturer was the highest factor contributing to the failure of students with $M=4.96, S D=1.216$ at a high views and perceptions of the respondents were as follows:

My communication with lecturers is not too good because I am older than them.. sometimes I felt just a little bit hurt with their words.. but sometimes I'm ok with them.. but actually, I have no problem with a few single 
lecturers. Even their teachings are very poor but I am still respecting my lecturers. I know my lecturers well and they are still my lecturers till the ends even some of them seem do not like me. But as students, we have follow their instructions.. some lecturers are very kind depend on situation and time...but, I am not too disappointed with my destiny to have lectures like this. We have to accept it right... but, there are lecturers who do not respect me as a student. We're too old, please treat us like boys. That's why we feel very difficult to communicate with these lecturers.. TESL is not an easy field to study via distance learning..

(INF1/East/25.2.2014).
However, the factor of teaching aids was the least important factor with $M=2.84, S D=1.146$. The findings were in line with the interviews. The views and perceptions of the respondents were as follows:

... we are not teens anymore.. this means that lecturers have to teach using teaching aids... sometimes they did not bring any teaching aids, that is why it was difficult for us to understand. Sometimes we are thinking that what the lecturer is doing in front of the class.. we do not understand anything.. My perception is, our lecturers may be tired in teaching on weekends.. that is why they teach us without using any tools...

(INF2/Sarawak/8.3.2014).

Table 4. Facility Factors

\begin{tabular}{|c|c|c|c|c|c|c|c|c|c|}
\hline & & \multicolumn{2}{|c|}{ Not Related } & \multicolumn{3}{|c|}{ Related } & \multirow[b]{2}{*}{ Mean } & \multirow[b]{2}{*}{ Standard Deviation } & \multirow[b]{2}{*}{ Level } \\
\hline S.N. & Item & SNR N (\%) & NT N (\%) & QR N (\%) & R N (\%) & SR N (\%) & & & \\
\hline 1 & Toilet cleanliness & $14(35)$ & $12(30)$ & $4(10)$ & $6(15)$ & $4(10)$ & 3.24 & .867 & Average \\
\hline 2 & Number of tables and chairs & $12(30)$ & $4(10)$ & $10(25)$ & $8(20)$ & $6(15)$ & 3.25 & .905 & Average \\
\hline 3 & LCD projector & $4(10)$ & $4(10)$ & $14(35)$ & $12(30)$ & $10(25)$ & 3.31 & .972 & Average \\
\hline 4 & Internet network & 2 (5) & 6 (15) & $10(25)$ & $12(30)$ & $10(25)$ & 3.39 & .972 & Average \\
\hline 5 & Internet password & $6(15)$ & $8(20)$ & $8(20)$ & $12(30)$ & $6(15)$ & 3.15 & 1.386 & Average \\
\hline \multirow[t]{2}{*}{6} & Classroom hygiene & $4(10)$ & $8(20)$ & $10(25)$ & $6(15)$ & $12(30)$ & 3.20 & 1.105 & Average \\
\hline & & \multicolumn{5}{|c|}{ Overall Mean } & 3.26 & .951 & Average \\
\hline
\end{tabular}

SNR $\div$ Strongly Not Related; NR $\div$ Not Related; QR $\div$ Quite Related; R $\div$ Related; SR $\div$ Strongly Related.

Table 4 showed that the facility factors contributing to the failure factors of TESL students in TGP at ITE with an overall mean with $M=3: 26, S D=0.951$ on average level. The study found that internet connection was the most relevant factor in contributing to this failure with $M=3: 39$, $S D=0.972$ on average level. The findings were in line with the interviews. The views and perceptions of the respondents were as follows:

...to me internet in the ITE is fine but sometimes the line sever is quite slow. It is because most of us always use apps in the ITE. We have to admit that without the internet, we cannot study with peace. Internet is one of the facilities, but the problem is we're not being allowed to use the middle time of study. Our lecturers always bothering our minds and said it's ok without using the internet... instead we are poor and not able to buy broadband.. we rarely use the internet during the class period.. if not, lecturers will get angry..

(INF2/South/18.2.2014).

However, internet password was the least important factor with $M=3: 15, S D=1,386$ on average level. The findings were in line with the interviews. The views and perceptions of the respondents were as follows:

..ITE's facilities can be considered $80 \%$ completed but there were $20 \%$ did not work properly. For example, some of us do not even know about the internet passwords in the ITE. Overdrive.. who know the passwords but sometimes the server is really cannot be connected. ITE administrators have to know that there are many TGP students using the internet network at a given time. That is why the server is so slow..

(INF1/North/12.2.2014)
Table 5 showed that the syllabus factors contributing to the failure factors of TESL students in TGP at ITE with an overall mean with $M=4: 12, S D=0.975$ on high level. The study found that TGP syllabus suitability was the most relevant factor contributing to this failure with $M=$ $4.67, S D=0.971$ at a high level. The findings were in line with the interviews. The views and perceptions of the respondents were as follows:

...chapters in the syllabus are actually give a burden.. this syllabus had been provided by ITE itself.. so, the syllabus of the institute is not suitable for us because we already come with our age and we are not like full-time students. I am telling you sir that studying at the institute is really giving a burden and very difficult. I think Ministry of Education should look up and make a new syllabus for our program. As I said before, we are not robots, we are educators.. besides, there are so many works to do in our studies.

\section{(INF1/South/16.2.2014)}

However, learning period was the least important factor with $M=3: 38, S D=1.039$ on average level. The findings were in line with the interviews. The views and perceptions of the respondents were as follows:

..I think two years are enough for us to study in this program to avoid our minds get in dizziness. This is just my opinion. Some of TGP syllabus contents are not suitable for us. Therefore, Ministry of Education should reduce the amount of syllabus and at the same time reduce our study's period. This is because we are experienced teacher. We do not need to learn more and we already had learnt some of the topics in the syllabus.

(INF1/South/26.2.2014).

Table 5. Syllabus Factors

\begin{tabular}{|c|c|c|c|c|c|c|c|c|c|}
\hline & & \multicolumn{3}{|c|}{ Not Related } & \multicolumn{3}{|c|}{ Related } & & \\
\hline S.N. & Item & SNR N (\%) & NT N (\%) & QR N (\%) & R N (\%) & SR N (\%) & Mean & Standard Deviation & Level \\
\hline $\mathbf{1}$ & Syllabus appropriateness & $\mathbf{2 ~ ( 5 )}$ & $\mathbf{0 ~ ( 0 )}$ & $\mathbf{0 ~ ( 0 )}$ & $\mathbf{1 6}(\mathbf{4 0})$ & $\mathbf{2 2 ~ ( 5 5 )}$ & $\mathbf{4 . 6 7}$ & $\mathbf{. 9 7 1}$ & High \\
\hline 2 & Level difficulty & $0(0)$ & $0(0)$ & $2(5)$ & $14(35)$ & $24(60)$ & 4.61 & .904 & High \\
\hline 3 & Theory learning & $0(0)$ & $2(5)$ & $2(5)$ & $14(35)$ & $22(55)$ & 4.33 & .959 & High \\
\hline 4 & Practical learning & $0(0)$ & $2(5)$ & $4(10)$ & $8(20)$ & $26(65)$ & 3.61 & .942 & Average \\
\hline 5 & Learning period & $2(5)$ & $2(5)$ & $2(5)$ & $6(15)$ & $28(70)$ & 3.38 & 1.039 & Average \\
\hline \multicolumn{7}{|c|}{ Overall Mean } \\
\hline
\end{tabular}

SNR $\div$ Strongly Not Related; NR $\div$ Not Related; QR $\div$ Quite Related; R $\div$ Related; SR $\div$ Strongly Related. 
Table 6. School Factors

\begin{tabular}{|c|c|c|c|c|c|c|c|c|c|}
\hline \\
\hline & & \multicolumn{2}{|c|}{ Not Related } & \multicolumn{3}{|c|}{ Related } & \multirow[b]{2}{*}{ Mean } & \multirow[b]{2}{*}{ Standard Deviation } & \multirow[b]{2}{*}{ Level } \\
\hline S.N. & Item & SNR N (\%) & NT N (\%) & QR N (\%) & R N (\%) & SR N (\%) & & & \\
\hline 1 & Administrator encouragement & $0(0)$ & $2(5)$ & $4(10)$ & $8(20)$ & $26(65)$ & 3.15 & .932 & Average \\
\hline 2 & Burden of work & $0(0)$ & $0(0)$ & $2(5)$ & $14(35)$ & $24(60)$ & 4.23 & 1.078 & High \\
\hline 3 & School program the on weekends & $0(0)$ & $2(5)$ & $2(5)$ & $14(35)$ & $22(55)$ & 3.25 & 1.016 & Average \\
\hline \multirow[t]{2}{*}{4} & Importance of official duties & $2(5)$ & $0(0)$ & $0(0)$ & $16(40)$ & $22(55)$ & 3.18 & 1.159 & Average \\
\hline & & \multicolumn{5}{|c|}{ Overall Mean } & 3.45 & 1.046 & Average \\
\hline
\end{tabular}

SNR $\div$ Strongly Not Related; NR $\div$ Not Related; QR $\div$ Quite Related; R $\div$ Related; SR $\div$ Strongly Related

Table 6 showed that the school factors contributing to the failure factors of TESL students in TGP at ITE with an overall mean with $M=3: 45, S D=1.046$ on average level. The study found that burden of work was the most relevant factor in contributing to this failure with $M=4: 23$, $S D=1.078$ at a high level. The findings were in line with the interviews. The views and perceptions of the respondents were as follows:

...my school gives a lot of assignments to me... then, I have a lot of work to do including my study's assignments. Actually, school administrators already had known that we are learning in TGP, but they still burdened us with ridiculous works. We are so tired to bear all these works including school works. Now, we are working like a machine.

(INF1/Sabah/8.2.2014)

However, encouragement from administrators was the least important factor with $M=3: 15, S D=0.932$ on average level. The findings were in line with the interviews. The views and perceptions of the respondents were as follows:

...there is no support from my administrators. I am really hoping that they can understand my situation in ITE. My lecturers give a lot of assignment to be accomplished. Sometimes, school programs on weekends require a lot of manpower. So, we need to go to school and not to attend TGP classes.

(INF1/North/16.2.2014)

\section{Discussion and Implications}

In general, the impact on physical education students in TGP who failed in some courses was at a low level. However, the study also found that there were some impacts on the students who failed such as promotion of graduation effects, depression, low of self-esteem, salary increments and so on. Table 3 provided an overview that the lecturers' communication factor showed the highest level in contributing to the failure of the students. It indicated that lecturers' communication was very important for the distance learning process. There were five factors of the key themes arising from the study such as personal factors, lecturer factors, facility factors, syllabus factors and school factors.

Personal: Generally, researchers found that all students showed their determination to pursue a teaching bachelor although some limitations were faced. The limitation factors included their time, finance, distance between the ITE and home and health problems. However, all of the constraints need to be faced by the students sake for their future. This was proved by their presence to every single class on weekends. TGP students reported that they also got a full support and encouragement from families and colleagues in their schools.

Lecturer: Besides, TGP students' relationships with all lecturers were quite good except for some particular lecturers. TGP students reported that some of them were afraid to deal with arrogant lectures. This was because some ITE lecturers refused to be tolerant towards TGP students who had personal problems which could not be avoided. Due to that, some of the students were lacking motivation and encouragement because their lecturers seem to underestimate their abilities as ITE students.

Facility: Although the internet server at the institute was limited, the students reported that it was not a major problem because they used their own broadband. Besides, they understood that there were too many students using it. In addition, students also reported that they had to sacrifice their own money to buy TESL equipment costing more than RM1000 to ensure their studies were running smoothly.

Syllabus: Besides, students reported that they had to learn a high level syllabus which is beyond their abilities. Meanwhile, TGP students only had a short interaction session with only five meetings per semester. In other words, students felt that this mode of program was not suitable for TGP students and the syllabus should be improved. It was because duration of assignments given was very short and they did not have time to complete them in a time given. To overcome this problem, the students are willing to pursue an additional private tuition with a qualified partner in the sports field. It is indicating that the students have high aspirations to succeed and they are willing to sacrifice their time, energy and money to achieve their ambitions.

School: Schools including teachers and colleagues are generally given a full support and encouragement to the students who are in the program. In fact, some of them are granted exemption from attending school activities on the weekend if they have classes. This means their schools are always provided high supports to improve their knowledge and thus, help to enhance the overall professionalism.

\section{Conclusion}

The findings showed that the failure factors of TESL students in TGP at ITE were caused by an imbalance assessment system in which the weightage was 100\% based on exam-oriented. Next, most of them stated that they still have to perform coursework, although the weighted scores were not counted in the final examination. 
In addition, they also have intrinsic assignments as a schools teacher, to perform preparatory teaching and learning as well as additional duties to another.

At the same time, they also need to divide their time and concentrate on the task as a TGP student. Besides, the number of face to face interaction with lecturers is limited and they felt that the course work marks should be considered to help them to improve the exam scores. This causes them to feel so disappointed even they were doing the course work as best as possible. Following the failure, the students felt very sad, frustrated and stressed out to deal with colleagues and family members. Despite their desires to continue their studies to the degree level are still high, some of them are desperate and reluctant to pursue their studies again because of their ages and afraid to face the failure again.

\section{References}

[1] Sulaiman Fatimah, The concept of teaching through e-learning, Journal of Distance Education, 8(12), 18-27 (2012).

[2] Sulan Ibrahim, Lecturers teaching approaches and methods of distance education, Journal of Management Education, 8(3), 5466 (2010).

[3] Jamaluddin Khalid, Satisfaction of students through distance education, Journal of Distance Education, 2(13), 34-41 (2011)

[4] Rauzah N. A. M. A and Muhammad A. Z., Strengths and weaknesses of distance learning, Journal of Educational Administration and Management, 5(8), 32-43 (2013).

[5] Rosli Kamaruddin, Failure of distance education students in physical education, Journal of Physical Education, 9(2), 23-38 (2013).

[6] Halim Siti Hasanah, Self-learning techniques in distance students, Journal of Management Education, 2(8), 21-29 (2013). 